\title{
Age-Related Primary Cochlear Neuronal Degeneration in Human Temporal Bones
}

\author{
Chadi A. Makary ${ }^{1,2}$, Jennifer Shin $^{1,2}$, Sharon G. Kujawa ${ }^{1,2,3}$, M. Charles Liberman ${ }^{1,2,3}$, \\ and SAumil N. Merchant ${ }^{1,2,3}$ \\ ${ }^{1}$ Department of Otolaryngology, Massachusetts Eye and Ear Infirmary, 243 Charles Street, Boston, MA 02114-3006, USA \\ ${ }^{2}$ Department of Otology and Laryngology, Harvard Medical School, Boston, MA, USA \\ ${ }^{3}$ Eaton-Peabody Laboratories, Massachusetts Eye and Ear Infirmary, Boston, MA, USA
}

Received: 17 May 2011; Accepted: 26 June 2011; Online publication: 12 July 2011

\begin{abstract}
In cases of acquired sensorineural hearing loss, death of cochlear neurons is thought to arise largely as a result of sensory-cell loss. However, recent studies of acoustic overexposure report massive degeneration of the cochlear nerve despite complete hair cell survival (Kujawa and Liberman, J Neurosci 29:14077-14085, 2009). To assess the primary loss of spiral ganglion cells (SGCs) in human ears, neuronal counts were performed in 100 temporal bones from 100 individuals, aged newborn to 100 years, selected to include only cases with a normal population of inner and outer hair cells. Ganglion cell counts declined at a mean rate of 100 cells per year of life. There were no significant gender or inter-aural differences, and a slight increase in degeneration in the basal turn re upper turns was not statistically significant. The agerelated decline in SGCs was significantly less than that in prior studies that included ears with hair cell loss (Otte et al., Laryngoscope 88:1231-1246, 1978), but significantly more than for analogous data on vestibular ganglion cells in cases without vestibular hair cell loss (Velazquez-Villasenor et al., Ann Otol Rhinol Laryngol Suppl 181:14-19, 2000). The age-related decline in SGC counts may contribute to the wellknown decline in hearing-in-noise performance, and the data will help in interpretation of histopathological findings from temporal bones with known otologic disease.
\end{abstract}

Correspondence to: Saumil N. Merchant · Department of Otolaryngology Massachusetts Eve and Ear Infirmary 243 Charles Street, Boston, MA 02114-3006, USA. Telephone: +1-617-5733503; fax: +1-617-5733939; e-mail: Saumil_merchant@meei.harvard.edu
Keywords: spiral ganglion, cochlear neurons, histopathology, otopathology

\section{INTRODUCTION}

In the cochlear nerve, each spiral ganglion cell (SGC) sends a peripheral axon to synapse with hair cells in the organ of Corti, and a central axon to relay the sensory signals to neurons in the cochlear nucleus. After cochlear insults such as ototoxic drugs or acoustic overexposure, degeneration of sensory cells can be seen within days, whereas loss of SGCs is not visible for weeks to months (Liberman and Kiang 1978; Leake and Hradek 1988; McFadden et al. 2004). This difference in degenerative time course has long suggested that most SGC death in cases of sensorineural hearing loss occurs as a result of hair cell loss, and is therefore a type of "secondary" degeneration (Johnsson 1974; Spoendlin 1984). However, direct evidence has always been lacking as to which degenerative events are primary and which are secondary.

Recent work in mouse (Kujawa and Liberman 2009) has shown a slow (months to years) loss of SGCs after noise exposure, even when there is no loss of hair cells. Indeed, even in cases where cochlear thresholds have returned to normal, as measured by auditory brainstem responses (ABRs) or otoacoustic emissions (OAEs), there can be loss of up to $50 \%$ of SGCs. Given that all hair cells survive in these ears, this massive neural degeneration appears to be a "primary" result of the acoustic overexposure. Clearly, it is not "secondary" to loss of hair cells. 
Although the death of the SGC is slow, the synaptic degeneration under the hair cells is visible within $24 \mathrm{~h}$ (Liberman and Mulroy 1982; Robertson 1983; Puel et al. 1998). Thus, the SGCs are functionally disconnected from the sensory transducers immediately post exposure. Although the ABR and OAE thresholds recover within a few days, ABR amplitudes at suprathreshold levels remain permanently reduced in proportion to the neural loss. This type of diffuse SGC loss, although it need not affect behavioral thresholds (Schuknecht and Woellner 1953), may contribute to difficulties hearing in a noisy environment.

Since problems with hearing in noise are a wellknown complaint of aging humans, and since for many ears some component of human age-related hearing loss is probably noise-induced, it is important to assess the magnitude of primary neuronal degeneration in human temporal bones. There are roughly 35,000 SGCs in the normal ear from the first decade of life (Miura et al. 2002). Although prior studies have shown an agerelated decline in SGC counts, most included few $(<20)$ cases (Guild et al. 1931; Hinojosa et al. 1985; Pollak et al. 1987; Spoendlin and Schrott 1989, 1990; Ishiyama et al. 2001; Miura et al. 2002), and larger studies did not exclude ears with hair cell lesions (Otte-Garcia 1972; Otte et al. 1978; Kusunoki et al. 2004). Thus, the present study quantifies age-related primary cochlear neuronal degeneration in human, i.e., considering only cases where there was no loss of sensory cells.

\section{METHODS}

The material for the study came from the archival temporal bone collection at the Massachusetts Eye and Ear Infirmary. The bones were processed by the standard technique for study by light microscopy (Merchant 2010), including fixation, decalcification, celloidin embedding, serial sectioning at $20 \mu \mathrm{m}$ in the horizontal plane, and hematoxylin-eosin staining of every tenth section. SGC counts were performed in 100 ears from 100 individuals; 48 were right ears, while 52 were left ears. These 100 cases included 8-12 for each decade from 0 to 100 years of age. All bones were required to have (1) a normal population of inner and outer hair cells throughout the cochlea, as assessed by light microscopy and (2) no evidence of inner ear abnormality except that normally seen in aged ears, i.e., patchy cellular loss of the spiral ligament fibrocytes and thinning (atrophy) of the stria vascularis.

The technique used for SGC counts was that originally described by Schuknecht (Otte et al. 1978) and used subsequently by others for the spiral and Scarpa's ganglia in human temporal bones (Velazquez-Villasenor et al. 2000). All SGCs with nucleus and nucleolus were counted in each cochlear turn from every tenth section. To estimate total cell numbers (Table 1 and Fig. 1), SGC counts were multiplied by 10 to account for intervening sections and by 0.9 to correct for double-counting of split nucleoli at section interfaces. To assess the basal-apical gradient in SGC death, the ganglion was divided into segments: the two-turn ganglionic spiral was divided into four halfturns at the four tangent points (segments I, II, III and IV from base to apex), and the largest half turn, segment II, was further subdivided into upper and lower halves, to make all segments closer to equal size.

\section{RESULTS}

Of the 100 bones in the study, none had significant loss of inner or outer hair cells: 75 had no visible histopathological abnormalities in any structures of the middle or inner ear, seven had strial atrophy, 16 had inactive chronic otitis media (characterized by fibrocystic sclerosis of the middle ear and mastoid without active inflammation), and two had both strial changes and inactive chronic otitis media (Fig. 1).

\section{TABLE 1}

Cochlear neuronal cell counts for each segment versus age

\begin{tabular}{|c|c|c|c|c|c|c|c|c|}
\hline Age (years) & $n$ & $\begin{array}{l}\text { Mean age } \\
\text { (years) }\end{array}$ & Seg I (mean $\pm S D)$ & $\begin{array}{l}\text { Seg II lower } \\
\text { (mean } \pm S D)\end{array}$ & $\begin{array}{l}\text { Seg II upper } \\
\text { (mean } \pm \text { SD) }\end{array}$ & $\begin{array}{c}\text { Seg III } \\
(\text { mean } \pm S D)\end{array}$ & $\begin{array}{c}\text { Seg IV } \\
(\text { mean } \pm S D)\end{array}$ & $\begin{array}{c}\text { Total } \\
(\text { mean } \pm S D)\end{array}$ \\
\hline -10 & 12 & 3 & $4,479 \pm 1002$ & $226 \pm 503$ & $6,620 \pm 667$ & $946 \pm 908$ & $8,408 \pm 1,301$ & $33,679 \pm 3,439$ \\
\hline $11-20$ & 10 & 14 & $4,442 \pm 924$ & $6,016 \pm 615$ & $5,316 \pm 930$ & $6,944 \pm 1,102$ & $7,401 \pm 1,257$ & $0,128 \pm 3,734$ \\
\hline $21-30$ & 10 & 25 & $4,154 \pm 926$ & $5,646 \pm 914$ & $5,585 \pm 1,118$ & $7,391 \pm 1,247$ & $7,281 \pm 1,199$ & $30,273 \pm 3,879$ \\
\hline $31-40$ & 10 & 35 & $3,693 \pm 425$ & $5,269 \pm 761$ & $5,451 \pm 902$ & $6,929 \pm 883$ & $7,478 \pm 492$ & $28,820 \pm 2,782$ \\
\hline $41-50$ & 10 & 47 & $3,237 \pm 1,053$ & $4,835 \pm 910$ & $5,125 \pm 802$ & $6,611 \pm 757$ & $7,085 \pm 888$ & $26,922 \pm 3,018$ \\
\hline $51-60$ & 10 & 56 & $3,537 \pm 817$ & $4,951 \pm 812$ & $5,050 \pm 723$ & $6,096 \pm 862$ & $6,172 \pm 1,097$ & $25,787 \pm 3,848$ \\
\hline $61-70$ & 10 & 64 & $3,279 \pm 1,020$ & $5,102 \pm 614$ & $4,892 \pm 632$ & $6,653 \pm 738$ & $7,116 \pm 730$ & $27,042 \pm 2,674$ \\
\hline $71-80$ & 10 & 76 & $3,714 \pm 974$ & $5,220 \pm 1,170$ & $4,963 \pm 864$ & $6,215 \pm 1,281$ & $6,088 \pm 1,400$ & $26,200 \pm 4,491$ \\
\hline $81-90$ & 10 & 85 & $2,686 \pm 803$ & $4,278 \pm 898$ & $4,363 \pm 702$ & $5,458 \pm 927$ & $5,810 \pm 943$ & $22,946 \pm 3,402$ \\
\hline $91-100$ & 8 & 92 & $2,726 \pm 752$ & $3,828 \pm 472$ & $4,501 \pm 761$ & $5,587 \pm 1037$ & $5,802 \pm 1,349$ & $22,444 \pm 3,343$ \\
\hline
\end{tabular}




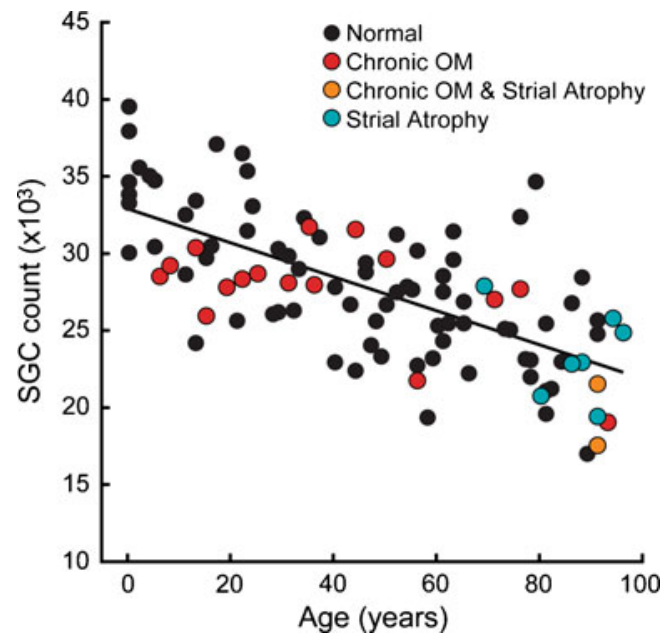

FIG. 1. Spiral ganglion cell counts declined steadily with age from a mean of 33,679 in the first decade, to 22,444 in the tenth decade. Each point represents an estimate of the total number of spiral ganglion cells in one ear. Solid line represents the best-fit straight line. Each ear is coded according to the histopathological conditions noted for that case: only normal ears or those with signs of strial atrophy or chronic otitis media $(O M)$ were included.

In representative photomicrographs of the spiral ganglion from the upper basal turn at ages 2, 61 and 91 years, SGCs (red arrowheads) are easily distinguishable from Schwannn cells (black arrowheads), the only other nearby cell type, based on their clear size difference (Fig. 2). Even at the youngest age, the cell bodies of SGCs do not fill the bony channel known as Rosenthal's canal (dashed lines in Fig. 2B), as is typically seen in the ears of smaller mammals such as cat, guinea pig or mouse, etc. (Leake and Snyder 1989; Miller et al. 1997; Kujawa and Liberman 2009). From the three cases illustrated in Figure 2, the agerelated reduction in SGC counts is easily seen.

The data from all 100 ears in the present study (Fig. 1) show a clear and significant age-related decline in SGC counts $(p<0.001$, linear regression using age as a predictor of the total count). The total mean count for ages $0-10$ years was 33,679 . For individuals from 91 to 100 years old, the mean count was 22,444, i.e., a mean reduction of $30 \%$. Several functions were used to fit the relation between SGC counts and age. The best fit was a linear regression (solid line in Fig. 1), where $\mathrm{SGC}=32,913-(100.25 \times$ age in years $)$. The $95 \%$ confidence interval for the age coefficient was -133.82 to -86.68 , and for the intercept was 31,596 to 34,230 . Quadratic and cubic relationships were also evaluated, but neither improved the goodness of fit.

Although there were relatively few cases in this study with informative medical histories, there were three for which a history of noise exposure was explicitly noted: a 28-year-old man who worked as a carpenter, a 40-year-old man with temporary threshold shift following accidental discharge of a gun near his ears 5 years prior to death, and a 46-year-old man who had worked in a printing press. Results from these ears are indicated by the arrows in Figure 3A; it is noteworthy that two of the three had SGG counts well below the age-adjusted mean values.

There were no significant gender or inter-aural differences (Fig. 3). Apical-basal gradients in agerelated SGC losses are considered in Figure 4. The segment-by-segment analysis in Figure 4A (mean data) and B (best-fit straight lines) suggests that the loss is worse in the basal turn, i.e., segments I and lower II. However, these differences were not statistically significant; hypothesis testing was performed using the $95 \%$ confidence intervals for the coefficient of age in linear regression models using age as the primary predictive variable for each segment. Detailed segment-by-segment counts are listed in Table 1.

Recent audiograms were available for a subset of the cases in the present study. The mean hearing levels for each age group show an age-related decline in sensitivity (Fig. 5A). Thresholds remain close to normal for the first six decades of life, showing marked deterioration only after age 60. In contrast, the neuronal degeneration shows a steadier progression with an earlier onset

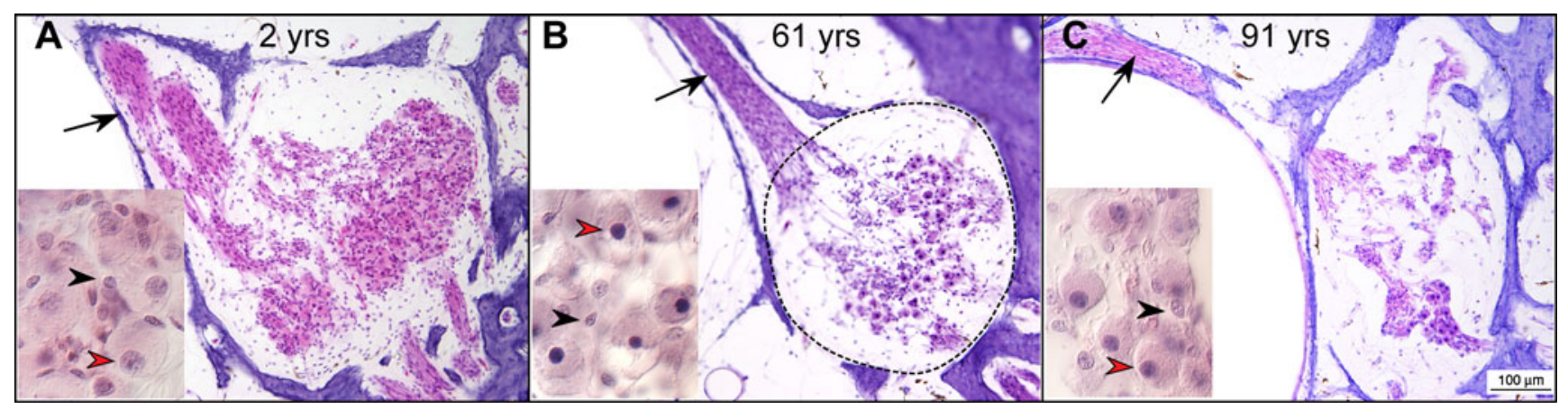

FIG. 2. Photomicrographs of the spiral ganglion in the upper basal turn from representative cases aged 2, 61 and 91 years, as indicated. The black arrow in each large panel points to the bundles of peripheral axons of cochlear nerve fibers in the osseous spiral lamina. The approximate outline of Rosenthal's canal is shown by the dashed line in panel B. Scale bar in C applies to all three large panels. The small inset in each panel shows a high-power view of some of the cells in Rosenthal's canal. The red arrowheads indicate spiral ganglion cells, characterized by a diffuse pink cytoplasm with a darker centrally located nucleus. The black arrowheads point to Schwann-cell nuclei: their cytoplasm is not easily seen. 

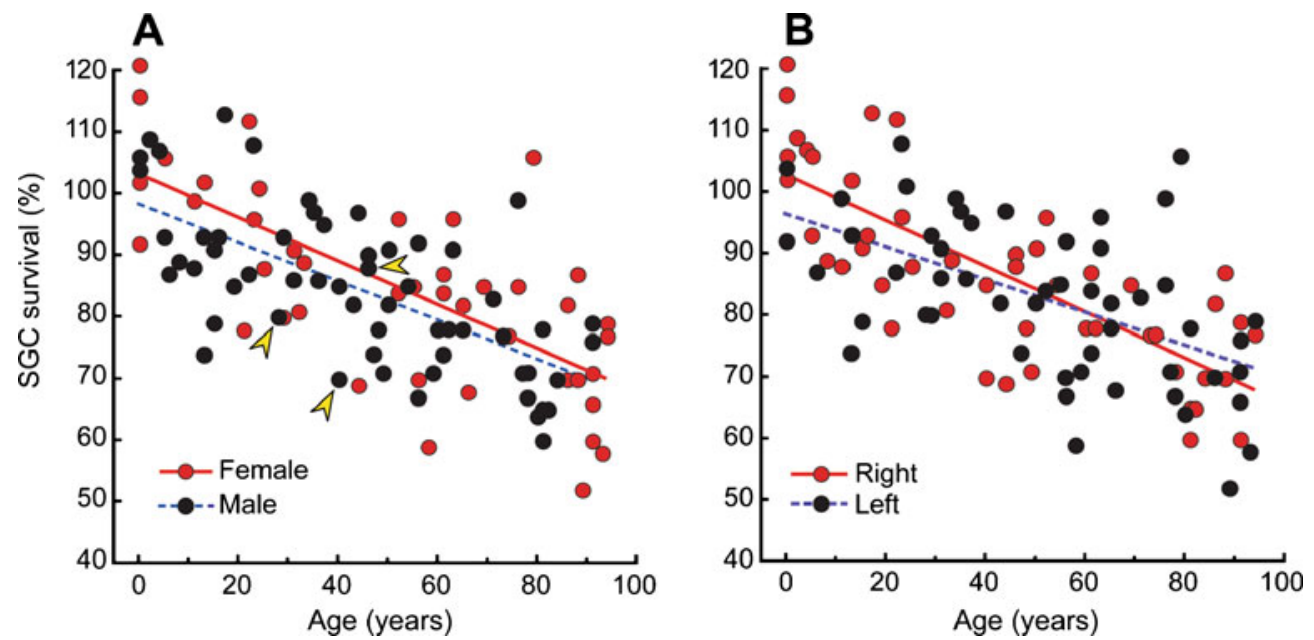

FIG. 3. No significant gender (A) or inter-aural (B) differences were seen. Spiral ganglion cell counts here are normalized to the mean value at birth extrapolated from the best-fit straight line from Figure 1. Arrowheads in (A) indicate the three individuals with unambiguous noise-exposure history. See text for further details.

throughout the entire cochlear spiral (Fig. 5B): compare, for example, the audiometric and neuronal data for the $51-60$ year group.

\section{DISCUSSION}

The factors influencing survival of SGCs in the mammalian cochlea have been studied by correlative histopathological analysis (Spoendlin 1975; Keithley and Feldman 1982; Suzuka and Schuknecht 1988; Sugawara et al. 2005) and by molecular biological approaches (Stankovic et al. 2004). Histopathological studies of acquired sensorineural hearing loss, in both animal models and human temporal bone material, have shown dramatic ( $>50 \%$ ) SGC degeneration in cochlear regions with massive hair cell loss (Leake and Hradek 1988; Miller et al. 1997; McFadden et al. 2004). Loss of IHCs appears to be particularly relevant, because $95 \%$ of SGCs, i.e., the type-I cells, make synaptic contact only with IHCs (Spoendlin 1972). However, IHC loss after cochlear insult is often combined with loss of supporting cells, and even complete loss of the organ of Corti, especially in the basal half of the cochlea. Thus, it has been difficult, from histopathological correlations, to assess the relative importance of hair cells vs. supporting cells in the trophic support of SGCs in the adult cochlea. The existing evidence suggests that both are important (Sugawara et al. 2005).

Several lines of evidence suggest that the neurotrophins BDNF and NT-3 are the critical signals for SGC survival in the mature ear (Miller et al. 1997; Stankovic et al. 2004; Gillespie and Shepherd 2005).
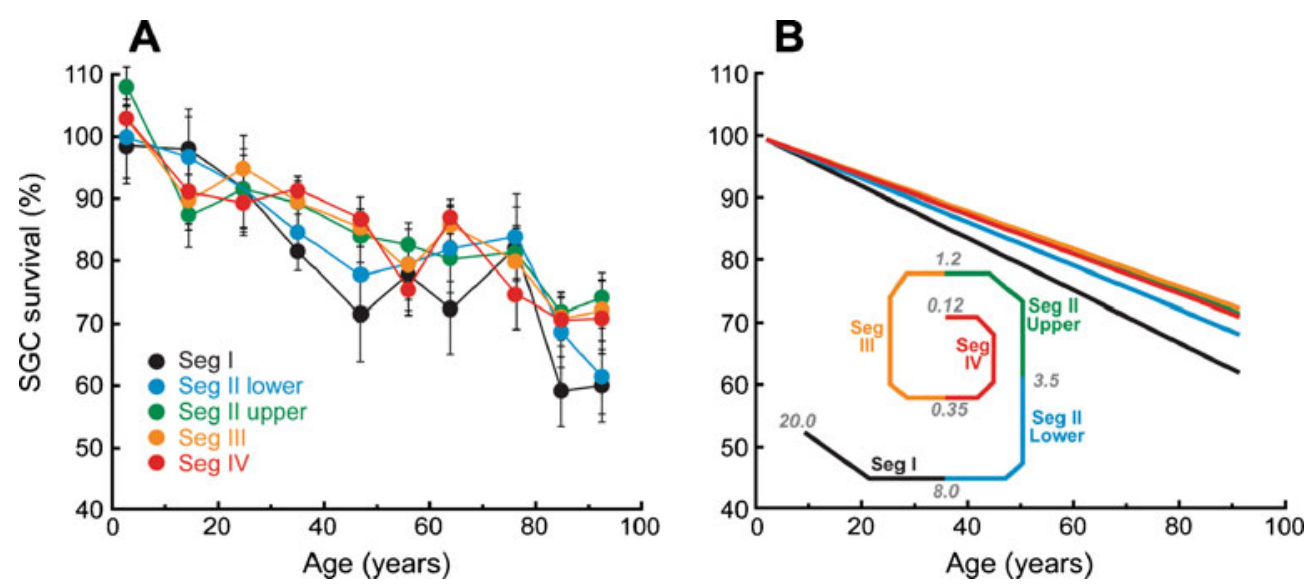

FIG. 4. The rate of spiral ganglion cell loss with age is similar in all cochlear locations. A Mean spiral ganglion cell counts $( \pm$ SD) for each decade of age are plotted for each cochlear segment, normalized to the value at birth as described in Figure 3. B Regression lines for the data from each segment. Although the best-fit decline is steeper for the two most basal regions, the differences were not statistically significant. Schematic inset to B shows the relative locations of the five cochlear segments and the approximate cochlear frequency values at the segment boundaries. 
A

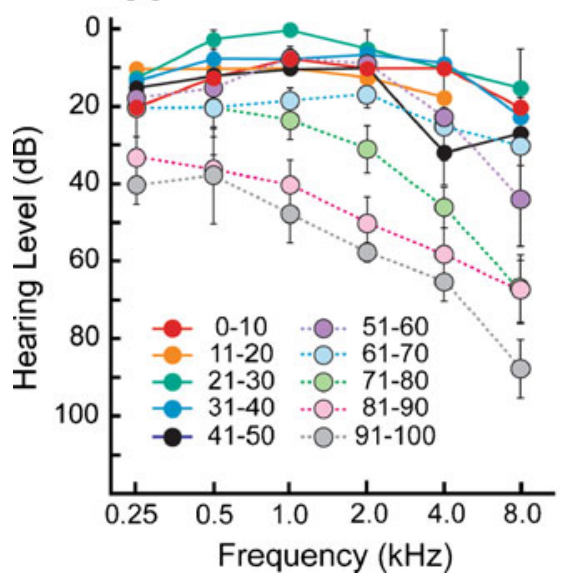

B

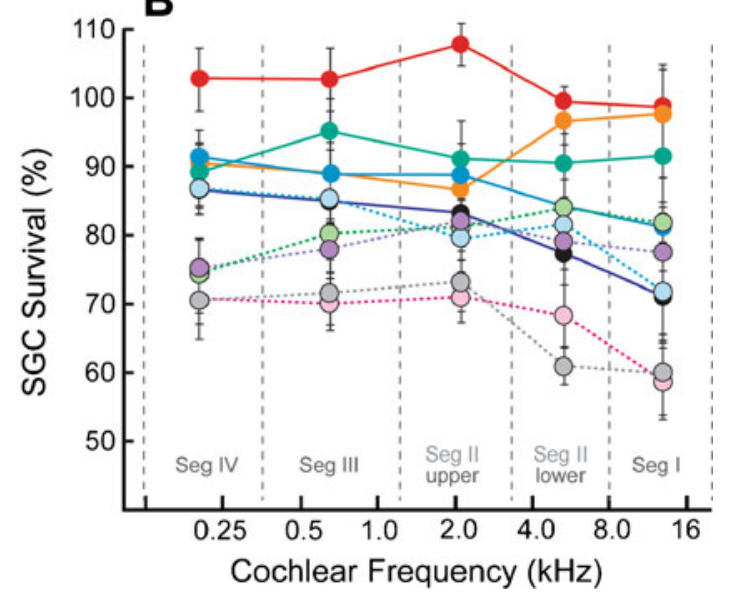

FIG. 5. Comparison of the age-related decline in audiometric data (A) and in the spiral ganglion cell survival plotted as a function of cochlear location/frequency $(\mathbf{B})$ : data shown are means and standard errors. Audiograms were available for only a subset of the ears in the study: $2 / 12$ for $0-10$ years; $2 / 10$ for $11-20 ; 2 / 10$ for $21-30 ; 4 / 10$ for $31-40 ; 3 / 10$ for $41-50 ; 4 / 10$ for $51-60 ; 3 / 10$ for $61-70 ; 6 / 10$ for $71-80 ; 5 / 10$ for $81-90 ; 2 / 8$ for 91-100. Ganglion cell counts are normalized as described in Figure 3. Cochlear location is converted to frequency according to the map derived by Schuknecht (Merchant 2010).

These neurotrophins are normally released by both hair cells and supporting cells in response to signals released from the cochlear nerve terminals in the IHC area (Stankovic et al. 2004; Sugawara et al. 2007). Transgenic mice in which this signaling pathway is disrupted by expression of a dominant negative receptor in supporting cells show SGC death, without hair cell loss, soon after onset of transgene expression (Stankovic et al. 2004). Guinea pigs with aminoglycoside-induced degeneration of the organ of Corti show massive SGC loss within a few weeks; however, this neuronal death can be completely rescued by cochlear perfusion of a neurotrophin cocktail including both NT-3 and BDNF (Miller et al. 1997; Gillespie and Shepherd 2005).

Our study found a significant loss of SGCs with age, averaging $\sim 1,000$ cells per decade, despite the fact that none of the ears analyzed had any loss of inner or outer hair cells. As shown in Figure 6, this rate of degeneration was significantly less than that seen in a prior temporal bone study (Otte et al. 1978), which showed an average loss of $\sim 1850$ SGCs per decade, using exactly the same techniques. However, the prior study included cases with sensory presbycusis, noise-induced hearing loss, etc., where parts of the cochlea, especially in the basal half, likely had significant loss of hair cells as well as supporting cells. The present dataset, explicitly excluding cases with hair cell loss, provides a better baseline for comparison in future temporal bone studies, if the aim is to assess how much SGC loss is due to causes other than aging per se.

The difference in severity of SGC degeneration, depending on the survival of hair cells and/or supporting cells, is consistent with the view that neurotrophin release from the sensory epithelium is critical for continued SGC survival. The neurotrophin NT-3 is normally expressed in a decreasing gradient from apex to base and in decreasing amounts with increasing age, at least in the mouse cochlea (Sugawara et al. 2007). Thus, the slow death of SGCs seen in the present study may arise at least in part, from a slow decrease in neurotrophin expression by aging cells in the organ of Corti, despite the survival of the entire sensory epithelium. The rate of neuronal death in the present study (1,000 cells per decade) was significantly more than that seen in a prior study of vestibular neurons (VelazquezVillasenor et al. 2000), which, using the same techniques, found an average loss of only 570 cells per decade.

The reason for increased age-related neuronal death in the cochlear vs. vestibular branches of the VIIIth nerve is not clear. However, a significant factor

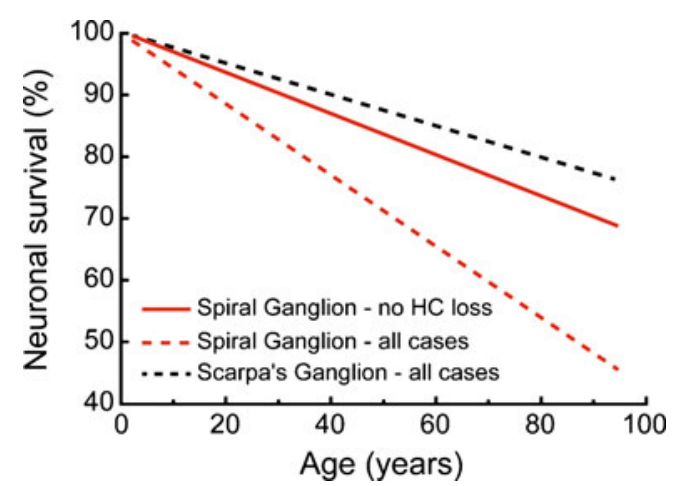

FIG. 6. Rate of age-related loss of spiral ganglion cells in the present study (red solid line) was significantly slower than that in a prior report that included all cases, regardless of the degree and extent of hair cell loss (red dashed line; Otte et al. 1978). The age-related loss reported for vestibular neurons in Scarpa's ganglion (dashed black line; VelazquezVillasenor et al. 2000) was significantly slower than that seen in either spiral ganglion study. Each graph is the best-fit straight line to the raw data from the respective study. 
may be the kind of primary neuronal degeneration that has recently been observed in both mice and guinea pigs after acoustic overexposures: even when noiseinduced threshold shifts were reversible, and no hair cell loss occurred, a slow-onset loss of roughly $50 \%$ of the SGCs was observed (Kujawa and Liberman 2009). Although the SGC death was slow to appear, requiring months to years, the degeneration of peripheral nerve terminals under the IHCs was seen immediately $(24 \mathrm{~h})$ post exposure. This reaction at the synapse between hair cell and SGC is probably a type of neural excitotoxicity (Puel et al. 1998), similar to that observed at other glutamatergic synapses in the nervous system. The slow SGC death may arise due to loss of the unmyelinated nerve terminal within the organ of Corti and from the resultant interruption of the normal neurotrophin signaling system involving communication between the nerve terminal and the cells of the organ of Corti.

Although the medical records from the cases in the present study contained few explicit references to noiseexposure history, two of the three that did showed a particularly low SGC count. Despite the paucity of explicit noise-exposure references, it seems likely that repeated and long-lasting overstimulation of the cochlear nerve is more unavoidable in modern society than overstimulation of the vestibular nerve. Thus, excitotoxicity from chronic, noise-induced, neural overstimulation may be a significant contributor to the age-related decline in SGC counts observed here.

In the absence of hair cell loss or damage, diffuse SGC degeneration does not affect audiometric thresholds. Indeed, even massive surgical lesions of the cochlear nerve, eliminating $50 \%$ to $90 \%$ of the fibers, do not cause measurable threshold shifts in behaviorally trained animals (Schuknecht and Woellner 1953). Clearly the redundancy of afferent innervation, whereby a single IHC is innervated by $10-30$ cochlear nerve fibers depending on species and cochlear location (Liberman et al. 1990; Hashimoto et al. 1990; Stamataki et al. 2006), is not designed to facilitate threshold detection of pure tones in a quiet environment. Given the probabilistic nature of cochlear nerve response (Kiang et al. 1965), it seems more likely that this redundancy is most useful for hearing complex stimuli like speech in a noisy environment. If true, the present results may help to explain the common audiometric finding among older individuals that the threshold losses seen in the audiogram are often inadequate to explain the handicap seen or reported for speech in noise.

\section{ACKNOWLEDGEMENTS}

We thank Jon Pack for the photomicrographs. This work was supported by NIH grants U24 DC008559 (SNM), R01 DC0188 (MCL) and R01 DC8577 (SGK).

\section{REFERENCES}

GILLESPIE LN, SHEPHERD RK (2005) Clinical application of neurotrophic factors: the potential for primary auditory neuron protection. Eur J Neurosci 22:2123-2133

Guild SR, Crowe SJ, Bunch CC, Polvogt LM (1931) Correlations of differences in the density of innervation of the organ of Corti with differences in the acuity of hearing, including evidence as to the location in the human cochlea of the receptors for certain tones. Acta Otolaryngol 15:269-308

Hashimoto S, Kimura RS, Takasaka T (1990) Computer-aided threedimensional reconstruction of the inner hair cells and their nerve endings in the guinea pig cochlea. Acta Otolaryngol 109:228-234

Hinojosa R, Seligsohn R, Lerner SA (1985) Ganglion cell counts in the cochleae of patients with normal audiograms. Acta Otolaryngol 99:8-13

Ishiyama A, Agena J, Lopez I, TANG Y (2001) Unbiased stereological quantification of neurons in the human spiral ganglion. Neurosci Lett 304:93-96

Johnsson LG (1974) Sequence of degeneration of Corti's organ and its first-order neurons. Ann Otol Rhinol Laryngol 83:294-303

KeIthley EM, Feldman ML (1982) Hair cell counts in an age-graded seroes of rat cochleas. Hear Res 8:249-262

Kiang NYS, Watanabe T, Thomas EC, Clark LF (1965) Discharge patterns of single fibers in the cat's auditory nerve. MIT Press, Cambridge

Kujawa SG, Liberman MC (2009) Adding insult to injury: cochlear nerve degeneration after "temporary" noise-induced hearing loss. J Neurosci 29:14077-14085

Kusunoki T, Cureoglu S, Schachern PA, Baba K, Kariya S, Paparella MM (2004) Age-related histopathologic changes in the human cochlea: a temporal bone study. Otolaryngol Head Neck Surg 131:897-903

Leake PA, Hradek GT (1988) Cochlear pathology of long term neomycin induced deafness in cats. Hear Res 33:11-33

LEAKE PA, SNYDER RL (1989) Topographic organization of the central projections of the spiral ganglion in cats. J Comp Neurol 281:612-629

Liberman MC, Kiang NY (1978) Acoustic trauma in cats. Cochlear pathology and auditory-nerve activity. Acta Otolaryngol Suppl 358:1-63

Liberman MC, Mulroy MJ (1982) Acute and chronic effects of acoustic trauma: cochlear pathology and auditory nerve pathophysiology. In: Hamernik RP, Henderson D, Salvi R (eds) New perspectives on noise-induced hearing loss. Raven Press, New York, pp 105-136

Liberman MC, Dodds LW, Pierce S (1990) Afferent and efferent innervation of the cat cochlea: quantitative analysis with light and electron microscopy. J Comp Neurol 301:443-460

McFadden SL, Ding D, Jiang H, Salvi RJ (2004) Time course of efferent fiber and spiral ganglion cell degeneration following complete hair cell loss in the chinchilla. Brain Res 997:40-51

Merchant SN (2010) Methods of removal, preparation and study. In: Merchant SN, Nadol JB (eds) Schuknecht's pathology of the ear, 3rd edn. People's Medical Publishing House-USA, Shelton

Miller JM, Chi DH, O'Keeffe LJ, Kruszka P, Raphael Y, Altschuler RA (1997) Neurotrophins can enhance spiral ganglion cell survival after inner hair cell loss. Int J Dev Neurosci 15:631-643

Miura M, SANdo I, Hirsch BE, OrITAY (2002) Analysis of spiral ganglion cell populations in children with normal and pathological ears. Ann Otol Rhinol Laryngol 111:1059-1065

Otтe J, Schuknecht HF, KerR AG (1978) Ganglion cell populations in normal and pathological human cochleae. Implications for cochlear implantation. Laryngoscope 88:1231-1246

OtTE-GARCiA J (1972) Estudios del ganglio espiral. Rev Otorrinolaringol $32: 58-68$ 
Pollak A, Felix H, Schrott A (1987) Methodological aspects of quantitative study of spiral ganglion cells. Acta Otolaryngol Suppl 436:37-42

Puel JL, Ruel J, Gervais d'Aldin C, Pujol R (1998) Excitotoxicity and repair of cochlear synapses after noise-trauma induced hearing loss. Neuroreport 9:2109-2114

RoBERTSON D (1983) Functional significance of dendritic swelling after loud sounds in the guinea pig cochlea. Hear Res 9:263-278

Schuknecht HF, Woellner RC (1953) Hearing losses following partial section of the cochlear nerve. Laryngoscope 63:441-465

Spoendlin HH (1972) Innervation densities of the cochlea. Acta Otolaryng 73:235-248

SpoendLIN H (1975) Retrograde degeneration of the cochlear nerve. Acta Otolaryngol 79:266-275

SpoENdLIN H (1984) Factors inducing retrograde degeneration of the cochlear nerve. Ann Otol Rhinol Laryngol 93:76-82

Spoendlin H, Schrott A (1989) Analysis of the human auditory nerve. Hear Res 43:25-38

Spoendin H, Schrott A (1990) Quantitative evaluation of the human cochlear nerve. Acta Otolaryngol Suppl 470:61-69, discussion 69-70
Stamataki S, Francis HW, Lehar M, May BJ, Ryugo DK (2006) Synaptic alterations at inner hair cells precede spiral ganglion cell loss in aging C57BL/6 J mice. Hear Res 221:104-118

Stankovic K, Rio C, Xia A, Sugawara M, Adams JC, Liberman MC, CORFAS G (2004) Survival of adult spiral ganglion neurons requires erbB receptor signaling in the inner ear. J Neurosci 24:8651-8661

Sugawara M, Corfas G, Liberman MC (2005) Influence of Supporting CELls on NEURONAL DEgeneration after hair cell loss. J Assoc Res Otolaryngol 6:136-147

Sugawara M, Murtie JC, Stankovic KM, Liberman MC, Corfas G (2007) Dynamic patterns of neurotrophin 3 expression in the postnatal mouse inner ear. J Comp Neurol 501:30-37

Suzuka Y, Schuknecht HF (1988) Retrograde cochlear neuronal degeneration in human subjects. Acta Otolaryngol Suppl 450:1-20

VelazQuez-Villasenor L, Merchant SN, Tsuji K, Glinn RJ, Wall C 3RD, RAUCH SD (2000) Temporal bone studies of the human peripheral vestibular system. Normative Scarpa's ganglion cell data. Ann Otol Rhinol Laryngol Suppl 181:14-19 